\title{
EDITORIAL
}

\section{Impact factors in biliary atresia}

'Looking at the problem of biliary atresia from the vantage point of 30 years' experience with the lesion, we can say with certainty that the jaundiced baby who has had no extrahepatic bile duct has been the most disappointing patient for the surgeon in the whole realm of lesions theoretically correctable by a surgical procedure. ${ }^{1}$

After early descriptions in the 18th and 19th centuries, surgical results were first reported in the early 20th century, and prior to the 1950s, survival of infants with biliary atresia was rare, the natural sequence being the development of cirrhosis with death from intractable liver failure.

In the 1960s, an undercredited physicist from Harvard, Thomas Kuhn, wrote his book The Structure of Scientific Revolutions wherein he introduces the world to 'paradigms' and 'paradigm shifts'. Two physicians have revolutionised the management and long-term survival of infants with biliary atresia, these being Morio Kasai and Thomas Starzl. Their interventions, the Kasai portoenterostomy and liver transplantation, respectively, represent 'paradigm shifts' in the management of biliary atresia, converting a uniformly fatal condition to one with a survival rate in excess of $80 \%$.

Prior to Kuhn's 1962 book, science was considered a 'rational endeavour in which knowledge is achieved through painstaking, day-to-day accumulation of data, facts, and minor discoveries'. Kuhn referred to this traditional approach as 'normal science. By comparison with Kasai and Starzl, and without minimising their exemplary contributions, perhaps the work of other researchers on the pathophysiology, advances in surgical technique, choleretics, steroids and antibiotics, are just 'normal science'?

Whatever one feels about people's respective contributions to this spectrum of progress, this special supplement of the South
African Medical Journal ${ }^{2-10}$ will hopefully provide useful insights into this enigmatic disease - from presentation, investigation and confirmation of diagnosis; through operative technique and perioperative care; and when this 'fails', empowering you as the clinician to care for your patient, hopefully bridging them to liver transplantation and ongoing survival.

\section{J A Loveland}

Department of Paediatric Surgery

Chris Hani Baragwanath Academic Hospital

Charlotte Maxeke Johannesburg Academic Hospital

University of the Witwatersrand

Johannesburg

loveland@wol.co.za

1. Koop CE. Biliary obstruction in the newborn. Surg Clin North Am 1976;56(2):373-377.

2. Grieve A, Davenport M. Maximising Kasai portoenterostomy in the treatment of biliary atresia: Medica and surgical options. S Afr Med J 2012;102(11):865-867. [http://dx.doi.org/10.7196/SAMJ.6120]

3. Hadzic N. Medical management of 'failing' Kasai portoenterostomy. S Afr Med J 2012;102(11):868871. [http://dx.doi.org/10.7196/SAMJ.6129]

4. Millar AJW. Solving difficult hepatobiliary problems in children. S Afr Med J 2012;102(11):872-875. [http://dx.doi.org/10.7196/SAM].6135]

5. Zuckermann M, Loveland JA. Selection and work-up for liver transplantation. S Afr Med 2012;102(11):876-878. [http://dx.doi.org/10.7196/SAM].6146]

6. Botha JF. Paediatric living donor liver transplantation. S Afr Med J 2012;102(11):879-880. [http:// dx.doi.org/10.7196/SAMJ.6261]

7. Loveland JA, Krog F, Beale P. A review of paediatric liver resections in Johannesburg: Expectation and preferred technique. S Afr Med J 2012;102(11):881-883. [http://dx.doi.org/10.7196/SAMJ.6204] 8. Bandika VL, Goddard EA, De Lacey R, Brown RA. Endoscopic injection sclerotherapy for bleeding varices in children with intrahepatic and extrahepatic portal venous obstruction: Benefit of injection tract embolisation.S Afr Med J 2012:102(11):884-887. [http://dx.doi.org/10.7196/SAMJ.6263]

9. Moore SW, Tshifularo N, Grobbelaar JI. Lessons from the hepatoblastoma-familial polyposis connection. S Afr Med J 2012;102(11):888-889. [http///dx doi.org/10.7196/SAMJ6138]

10. Zabiegaj-Zwick C, Nel E, Moore SW. Problems related to cytomegalovirus infection and biliary atresia S Afr Med J 2012;102(11):890-892. [http://dx.doi.org/10.7196/SAM].6163]

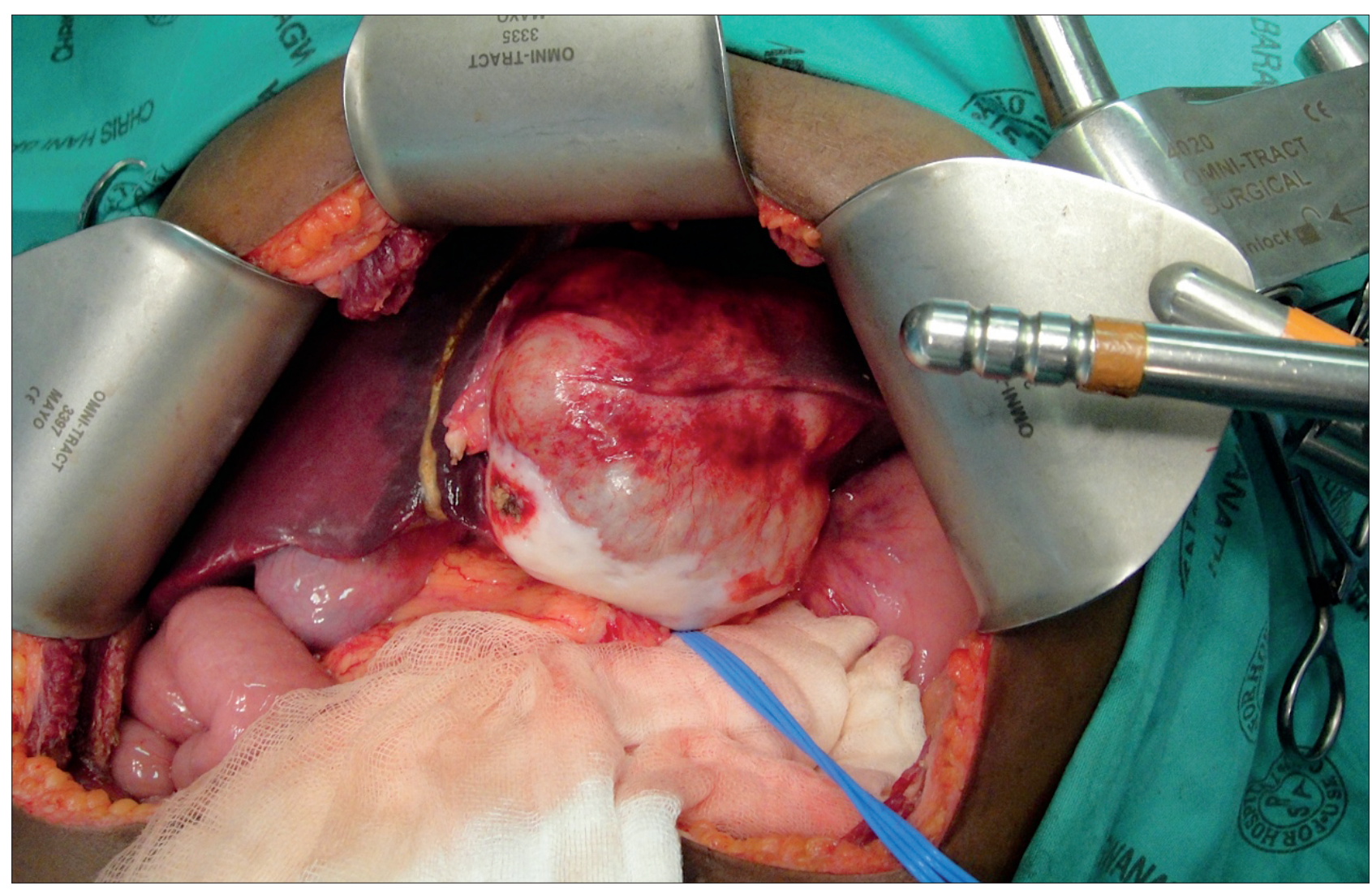

